\title{
XIV.
}

\section{Die Werththeorie bei Aristoteles und Thomas von Aquino.}

Ton

\section{Dr. Johann Žmave (Prag).}

Aristoteles als wissenschaftlichem Politiker konnte der Kernbegriff der nationalökonomischen Lehren nicht entgehen; hatte er auch wie E.M ey er in seiner "WirthschaftlichenEntwicklung desAlterthums" richtig betont, für die wirtschaftlichen Bedingungen und Grundlagen des von seinem Schüler, Alexander dem Grossen, geschaffenen Weltreiches nicht viel Sinn, und schwebte ihm auch nur der kleine Stadtstaat als Ideal eines Staates vor Augen, so hat er doch die Hauptbegriffe der politischen Oekonomie viel besser festgelegt und analysirt, als man gemeiniglich anzunehmen geneigt ist. Manche, die in Aristoteles nachgelesen haben, sind ihm nicht weit genug gefolgt, was schon A.Schüffle beklagte: „Allerdings ist die(se) Perle Aristotelischer Analyse von den Oekonomisten selten scharf erfasst worden" (Bau u. Leben d. soc. Körp. I. ${ }^{1}$ S. 256) und treffend behauptet (Wenckstern') auch von Marx, dass dieser dio „Lehre des grossen Forschers verstümmelte", dessen Beschreibung der Verwandlung des fieldes in Kapital wie auch dessen Theorio des Tauschwerthes, welche ilum seine Werth- und Mehrwerththeorie sammt den Phasentheorien der wirthschaftlichen Evolutionen und Revolutionen umzustossen drohte, mit Absicht unterdrückte.

i) In "Iarx" S. 158. 
Aber auch bei Thomas von Aquino finden wir feine nationalökonomische Untersuchungen, dio uns den grossen Scholastiker in einom anderen lichte erscheinon lassen als in jenem, in dem man ihn gewöhulich zeichnet.

Da die Werthprobleme gegenwärtig*) im Vordergrunde der principiellen nationalökonomischen Analysen stehen, dürfte es am Platze sein, eine gedrängte, zusammenhängende systematische Darstellung der diesbezüglichen aristotelischen Untersuchungen und Gedanken zu geben, zu welchen die Erläuterungen und Anschauungen des Aquinaten ergänzend hinzutreten sollen. -

Bezeichnend ist, dass Aristoteles über die prinzipiellen Begriffe der politischen Oekonomie in der Ethik handelt, allwo ${ }^{2}$ ) er über die Cardinaltugend der Gerechtigkeit spricht; die nationalökonomischen Fragen sind bei ihm aufs Innigste mit den ethischen verknüpft, von denen auch wir einige nur streifen wollen.

Um den wichtigsten ethischen Begriff hervorzuheben, ist nach Aristoteles gut dasjenige, was von allen begehrt wird:

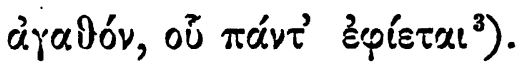

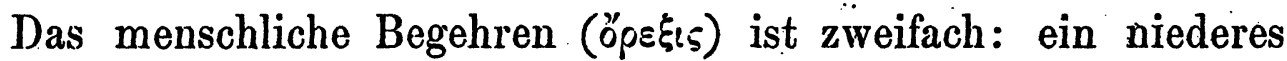

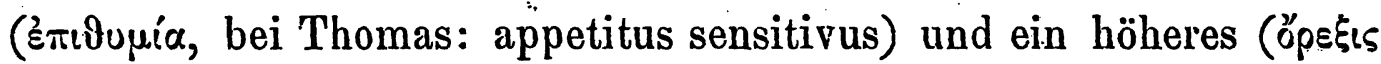

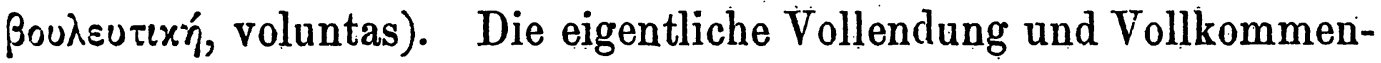
heit des menschlichen Wesens drückt sich im höheren Begehrungswie im höheren Verstandesvermögen aus. Die dem höheren Wollen entsprechenden Güter sind die geistigen und sittlichen Vollkommenen-

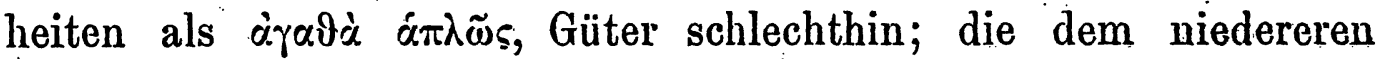

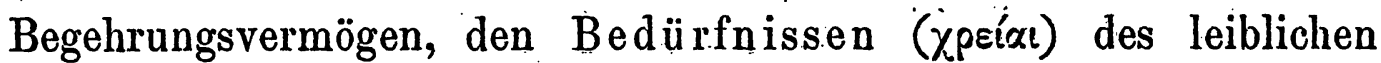

*) Wenckstern hebt neuerdings (in der "Beilage zur Allgem. Ztg." 25. - 26./4 d. J.) hervor, dass Marx erst verstańden werden wird, wenn in den Principien seines nationalökonomischen Systems die richtige aristotelische Werththeorie scharf getrennt sein wird von der Mehrwerththeorie der materialialistischen Geschichtsauffassung, und wendet sich diesbezüglich vor Allem an die Vertreter der österreichischen Schule (Böhm-Bawerk).

2) Eth. Nic. V. B. 5.-8. Cap. (nach Bekker); es wird im Folgenden lediglich auf die Nicomachische Ethik (Uebersetzung von A. Stahr) Rücksicht genommen.

3) Eth. Nic. I. B. 1. Cap. 
Lebens entsprechenden, welche der Mensch mit den Thieren gemein

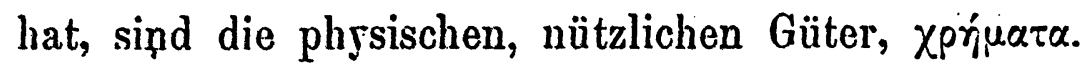

$\mathrm{Da}$ der Mensch kein rein geistiges, sondern ein essentiell ( $\tau \tilde{\eta}$ oujoí) aus Materie und Form zusammengesetztes Wesen ist, ist die Befriedigung der materiellen Bedürfnisse eine Voraussetzung für diejenige der geistigen; es kann für den Menschen kein vollendetes geistiges Leben ohne ein befriedigendes materielles Leben geben; die Güter jedoch, die diesem physischen Leben dienen (Nahrungs-

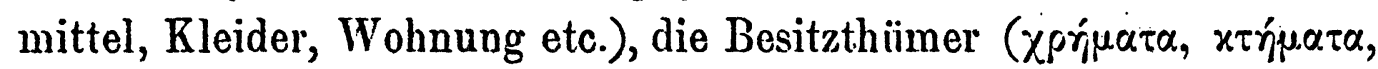
divitiae, bona exteriora sive utilia) sind stets zu jenen höheren intellectuellen und moralischen Gütern (Wissen, Tugend) als zu den bona simpliciter hingeordnet.

Die Politiker als Sozialethiker haben in erster Reihe für die gerechte Vertheilung dieser äusseren Güter und Reichthümer unter die Staatsangehörigen zu sorgen; diejenigen, welchen für die Beschaffung und'Erzeugung der Besitzthümer die Sorge obliegt, sind Helfershelfer der Politiker; die Erwerbs- und Finanzkunde ist sohin der Politik untergeordnet, was wir unten noch eingehender ausführen wollen.

Nach der aristotelischen Terminologie, welche dem gewöhnlichen Sprachgebrauch auf Grund der empirischen Beobachtungen entnommen ist, hat etwas insoferne einen Werth, als es ein Bedürfniss befriedigt: wie die Güter schlechthin, welche die höheren und edleren Bedürfnisse befriedigen, einen geistigen und moralischen Werth haben, so befriedigen die materiellen Güter die physischen Bedürfnisse und besitzen darum, indem sie als solche anerkannt werden, einen materiellen $\mathrm{Werth}^{4}$ ).

Inbezug auf diese materiellen Güter wollen wir Aristoteles weiter folgen.

Aristoteles unterscheidet da eine doppelte Classe der Güter;

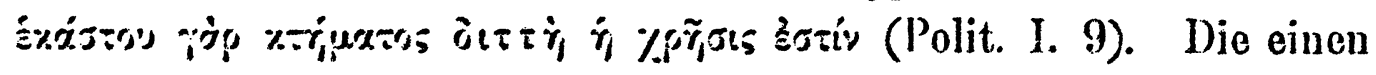
dienen direct zum specifisch eigenthümlichen Gebrauche (rixaix

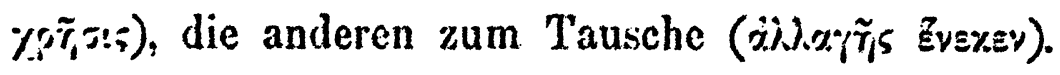

4, Es bezieht sich sprachlich der Ausdruck Wert (ał̌ia) auf die ïusseren Güter" (Ell. IV. 7). 
Unter den ersten, den Gebrauchsgütern, wie wir uns ausdrïcken, nimmt Aristoteles explicite keine Trennung mehr vor nach dem Gesichtspunkte, ob sie überall von Natur aus gegeben sind und nicht als Gegenstände menschlicher Vorsorge und Berechnung erscheinen - daher keinen ökonomischen Werth haben oder durch menschliche Arbeit erzeugt werden. Er sagt zwar, dass die Haushaltungskunde es mit dem blossen. Gebrauch, die Erwerbskunde aber mit der Erzeugung und Beschaffung zu thun

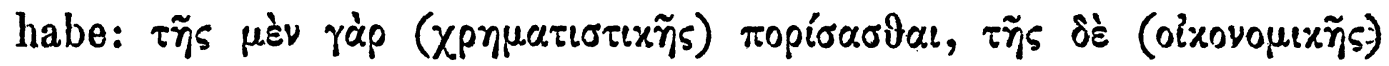
$\chi p \tilde{\eta} \sigma a \sigma \vartheta a \iota$. Implicite hat daher Aristoteles gewiss an jene Trennung gedacht, zumal er - wir werden übrigens diesbezügliche Stellen noch unten anführen - die bekannten Worte niedergeschrieben: „Wenn jedes der Werkzeuge auf Geheiss ... seine Aufgabe zu erfüllen vermöchte ..., wenn die Weberschiffe von selber webten und die Zitherschlägel von selber die Zither schlïgen, dann freilich bedürfte es für die Meister nicht der Gehilfen und für die Herren nicht der Sclaven". (Polit. I. 4.)

Wohl unterscheidet aber Aristoteles explicite zwischen Productiv- und Genussgütern, wie die moderne Nationalökonomie sich ausdrückt: „Nun aber sind die eigentlich sogenannten Werkzeuge zum Hervorbringen, die Besitzthümer aber zum praktischen Gebrauche. Denn das Weberschiff dient zur Hervorbringung eines Anderen ausser seinem blossen Gebrauche, Kleid und Bett dagegen zum letzteren allein. Und da die hervorbringende und technische und die (bloss) gebrauchende und praktische Thätigkeit sich $\cdot$ der Art nach unterscheiden, dabei aber beide Werkzeuge nöthig haben, so muss nothwendig unter diesen der nämliche Unterschied stattfinden. Leben aber heisst in der letzten und nicht in der ersten Weise thätig sein" (Polit. I. 4).

Jedoch nur wenige zum Leben nothwendige Güter werden von Natur ohne Weiteres geboten; um die meisten muss sich der Mensch plagen und anstrengen, für die meisten muss er arbeiten und Opfer bringen. Ja, jede menschliche „Gesellschaft bildet sich und besteht zu dem Zwecke, um irgend ein Gut zu erlangen. Um dessent-

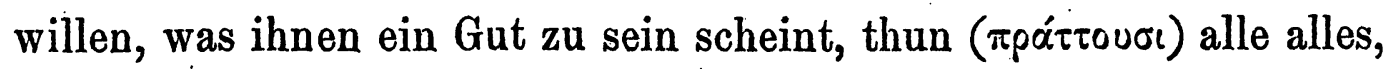
was sie thun." (Polit. I. 1.) Zunächst müssen physische Bedürf- 
nisse befriedigt, physische Güter geschaffen werden; Aristoteles neunt, das primitive Element der Gesellschaft, das Haus oder die Familie, mit anderen Autoren „Brotkorb- und Krippengenossenschaft"; „die für das gesammte tägliche Leben (für täglich wiederkehrende Bedürfnisse) bestehende Gemeinschaft ist naturgemäss das Haus ... diejenige Gemeinschaft aber, welche zunächst aus mehreren Familien zu einem über das tägliche Bedürfniss hinaus-

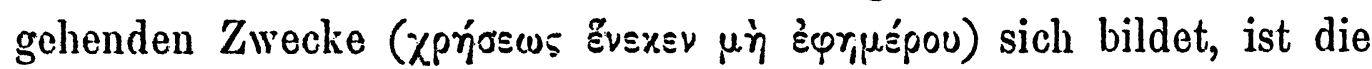
Dorfgemeinde, die am naturgemässesten als Colonie der Familie zu betrachten sein dürfte, und deren Glieder von Manchen Milchgenossen ... genannt werden ... Die aus mehreren Dorfgemeinden sich bildende vollendete und letzte Gemeinschaft nun aber ist bereits der Staat, welcher, wie man wohl sagen darf, das Endziel völligen Sichselbstgenugseins (aũiápxsıa) erreicht hat, indem er zwar entsteht um des blossen Lebens, aber besteht um des vollendeten Lebens willen." (Polit. I. 2.) Aristoteles hat auch schon dasjenige ausgesprochen, was zum berechtigten Theile der materialistischen Geschichtsauffassung gehört, dass nämlich die Art und Weise der Bedürfnissbefriedigung und der Besitzverhältnisse für die Structur der Gesellschaft von fundamentaler Bedeutung ist. Das wichtigste der durch menschliche Vorsorge und Arbeit zu befriedigenden Bedürfuisse ist dasjenige nach Nahrung. "Nun giebt es aber viele Arten von Nahrung und in Folge dessen auch vielerlei verschiedene Lebensweisen bei Menschen (und Thieren), denn da es unmöglich ist, ohne Nahrung zu leben, so sind es auch aben die Lnterschiede der Nahrung, welche auch die Unterschiede der Lebensweisen bei den lebendigen Geschöpfen hervorgebracht halen ... die Natur hat gemäss dem Zwecke der leichteren Gewinnung und bequemeren Auswahl dieser Nahrungsmittel auch ihre l.ebensweisen gesondert ... gar sehr vorschieden sind auch die Lubensweisen (der Menschen). Die trïgsten von ihnen sind die Comaden, denn diesen wird ihre Nahrung von den zahmen Thieren chne alle Mühe, (Arbeit, äves riovos) in unthätiger Weise zu Theil ... Der grïsste Theil der Menschen aber lebt vom Ackerlau uad von der Zucht von Früchten*). Lind das sind denn nun wohl

$\Rightarrow$ Alow in der Naturaluirthsohaft.

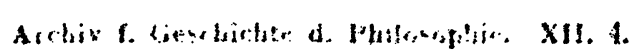


dic sämmtlichen Lebenswoisen, welche eine unmittelbar natürliclic

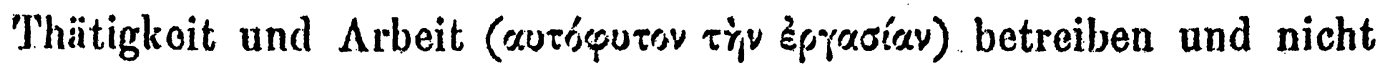

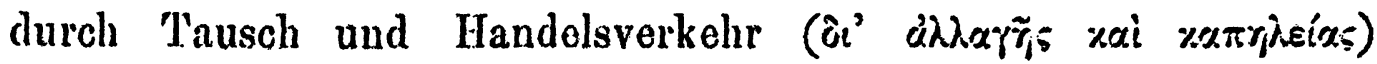
Nahrung und Unterhalt schaffen, das Nomaden-, das ackerbauende, das Rïuber-, das Fischer-, das Jägerleben, nur dass auch noch manche, um sich das Leben angenehmer $z$ u machen, mehrere dieser Lebensweisen verbinden, indem sie dem Mangel da, wo er hervortritt und das Sichselbstgenügen stört, abhelfen . . . worauf gerade das Bedürfniss hindrängt, darauf richten auch die Menschen ihre Lebensart hin." (Polit. I. 3.) Diejenige Kunst, welche sich mit der Beschaffung der erforderlichen Güter zu dem Zwecke befasst, dass sie unmittelbar dem Verbrauch und Gebrauch dienen, nennt unser Philosoph

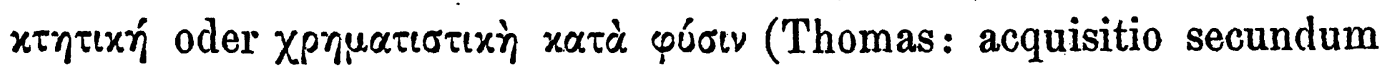
naturam), natürliche Erwerbskunst: so übt der Landmann, der sein Feld bebaut, um Korn für seine Familie zu ernten, der sein Vieh züchtet, um es zum Zwecke der Ernährung seiner Angehörigen zu schlachten, diese natürliche Erwerbskunst aus. Solche Güter dienen direct dem Gebrauche, der directen Bedürfnissbefriedigung; und insoferne sie diese natürlichen Bedürfnisse unmittelbar befriedigen, sind sie brauchbar, nützlich, werden als solche geschätzt, haben einen Gebrauchswerth, wie wir uns mit A. Smith ausdrücken. (Vgl. Anm. 6.)

$\mathrm{Da}$ die Bedürfnisse mannigfach sind und die menschliche Gesellschaft wohl nicht lange in der primitiven, alle für sie nothwendigen Güter selbst erzeugenden Communität gelebt haben mag, in welcher die individuellen und collectiven Bedürfnisse, leicht übersehbar, sachte ineinander übergingen und übergriffen, sondern gar. bald; schon wegen der verschiedenen Beschaffenheit und Ertragsfähigkeit derErde, die Arbeitstheilung ${ }^{5}$ ) eingetreten ist, so haben sich Gruppen gebildet, welche vor allem die Mittel für die eine Art der Bedürfnissbefriedigung erzeugten, so dass, um alle nothwendigen Güter zu haben,

5) „Aus zwei Aerzten wird keine Verkehrsgemeinschaft, wohl aber aus Arzt und Feldbauer und überhaupt aus Menschen, die in Lebensthätigkeit verschieden und nicht gleich sind, die dann aber eben mit einander ausgeglichen werden müssen. (Ethik Nic. V. 8.) 
die eine Gruppe ihre Producte gegen die Producte einer zweiten Gruppe, an. denen die erste einen Mangel hatte, eintauschen ${ }^{6}$ ) musste.

Der Tausch ( $\mu \varepsilon \tau \alpha \beta \beta \lambda \dot{\eta}, \alpha \lambda \lambda \alpha \gamma^{\gamma} \dot{\gamma}$, commutatio) ist ein bedeutungsvoller, der Gesellschaft ein neues Gepräge aufdrïckender Vorgang:

6) „Die Benutzung eines jeden Besitzthumes ist eine doppelte, und beidemale wird das Besitzthum als solches, aber nicht als solches in der gleichen Weise benutzt, sondern die eine Art ron Benutzung ist die dem Gegenstande eigenthümliche (oixeía), die andere nicht, z. B. den Schuh kann - man benutzen zum Anziehen, aber auch als Tauschmittel. Denn beides sind wirklich Benutzungsweisen des Schubes, insoferne auch der, welcher einem Anderen, der eines Schuhes bedarf, einen solchen für Geld oder Lebensnittel zum Tausche giebt, damit den Schuh als Schuh benutzt, aber nicht in der demselben specifisch eigenthümlichen Benutzungsweise; denn nicht zu dem Zwecke ist der Schuh gemacht, um als Tauschnittel zu dienen: Und ebenso verhält es sich mit allen anderen Besitzthümern: sie alle können als Tauschmittel verwendet werden, und dieser anfüngliche Tauschhandel ( $\mu \varepsilon \tau \alpha-$ $\beta\rangle_{1} \tau\left(x \dot{\gamma}_{i}\right)$ hatte einen durchaus natürlichen Ursprung, indem man von einem Gegenstande mehr und ron einem anderen weniger hat, als man bedarf. Andererseits aber ist gerade hieraus auch ersichtlich, dass das eigentliche Handels- und Geldgeschäft ( $\% \alpha \pi \eta \lambda(\%, \eta)$ nicht von Natur zur Erwerbskunst gehört. Nur soweit nämlich, als es für den Lebensunterhalt ausreichend war, musste sich nothwendig der Tausch erstrecken. In der ursprünglichsten Gemeinschaft daher, das ist im Hause, fand derselbe offenbar noch gar keinen Platz, sondern erst in der bereits erfolgten Erweiterung derselben. Denn die Hausgenossen hatten durchweg das Gleiche mit einander gemein; als aber die Wolnsitze und Besitzthümer getrennt wurden, da traten hinfort bei den Geneinlegliedern auch viele und bei verschiedenen verschiedene Mängel und Bellürfnisse ein, und da ward es denn nothwendig, je nach diesen Bedürfnissen die Gegenstānde derselben einander mitzutheilen, und zwar auf dem Wege des Tausches, wie es noch jetzt viele der ungriechischen völkerschaften machen, denn sie tauschen die nutabaren Gegenstănde selber gegeneinander, sic gehen und nehmen Wein für Getreide, und was dergleichen mehr ist: weiter aber gehen sie in Handel nicht. Ein solcher Tauscbhandel uun ist allerdings weder wider die Natur, noch bildet er bereits eine Klasse der Bereicherungskunst im engeren Sinne (des Geldgeschäftes), da er nur ent'tand, um die Jïngel auszufïllen, welche jener Sellistgenügsamkeit im Wege stehen, auf welche die Natur selber uns angewiesen hat. Aber aus liescu (natirlichen Tauchhandel) entsprang jene (Bereicherungskuust) in sehr hegrefficher Weise. Wenu da die gegenseitige Lnterstützung durch Finfulır les Mangelulen urid Ausfuhr des lielerflüssigen (allmällich) sich immer weiter irtlich ausdehute, verfiel man nothwendigerweise auf dic biufübrung des Geligehrauche... (Politik 1. 9 uach Susemill's Uehersctoung.) 
Gebrauchsgegenstïnde werden, wic wir das heute sagen, za Tauschgegenständen, Gebrauchswerthe zu'Tauschwerthen. Der'Tauschhandel, $\mu \varepsilon \tau \alpha \beta \lambda \eta \tau \iota x \eta^{\prime}$, ist jene Kunst, welche dic ökonomischen Güter der einen Art gegen die einer anderen eintauscht. Tauschwerth ist bei Aristoteles / sozusagen indirecter Gebrauchswerth: der Schuster, der lediglich Schuhe producirt, producirt sie zwar zu ihrem natürlichen Gebrauchszweck, zur Bekleidung der Füsse; allein er producirt sie von seinem Standpunkte aus zunächst, um andere, ihm direct nothwendige Gebrauchsgegenstände dafür einzutauschen: der Schuh hat einen Gebrauchswerth für den Consumenten, einen Tauschwerth für den Producenten.

Der Tausch ging ursprünglich so vor sich, dass man gegen eine gewisse Menge der einen Güterart eine gewisse der anderen - z. B. gegen 1 Rind x Paar Schuhe - eintauschte. Allein das genügte bald nicht mehr, der Tausch wurde komplicirter, und man musste für alle Güterarten einen eigenen, einheitlichen Tauschwerthmesser suchen. $\mathrm{Zu}$ dem Zwecke wurde das Geld eingeführt. „Nicht jedes der von Natur nothwendigen Güter liess sich nämlich leicht in die Ferne verführen, und so kam man dahin überein, zur Vermittlung des gegenseitigen Umtausches einen Gegenstand zu geben und zu nehmen, welcher, selbst zu den nutzbaren Dingen ${ }^{7}$ ) gehörig, zugleich noch den Vortheil eines leichthandlichen Gebrauches für das Fortschaffen hatte, wie Eisen, Silber und was weiter dahin gehört, und zwar so, dass man anfänglich seinen Werth einfach nach Grösse und Gewicht bestimmte, schliesslich aber es auch mit einem Prägezeichen versah, um sich die Mühe des Abwägens zu ersparen, indem nämlich jetzt dieser Stempel als Zeichen

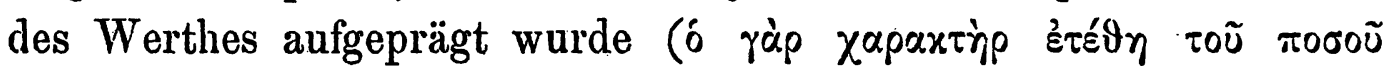

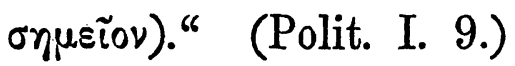

Doch wonach soll jener gemeinsame und einheitliche Werthmesser bestimmt werden? „Denn wie es keine Verkehrsgemeinschaft gäbe ohne Austausch, und keinen Austausch, wenn keine Gleichheit herzustellen wäre, so wäre auch keine Gleichheit möglich, wenn es keinen Massstab gäbe" (Eth. N. V. 8). Wonach wird also bestimmt, dass gerade 10 Betten für ein Haus, nicht mehr und

7) „Insoferne aus demselben Gefässe oder andere Geräthschaften verfertigt werden" commentiert Thomas diese Stelle. 
nicht weniger gegeben werden sollen? Damit die Werthgleichung ("Aequivalentform" nach Marx)

5 Betten $=1$ Haus $=10$ Minen (s. Eth. V 8)

aufgestellt werden bönne, muss es in diesen Dingen selbst etwas Gleiches geben.

Allerdings ist schon lange vor Aristoteles in der Wirthschaft alles auf das Geld zurückgeführt worden; und auch in seiner Ethik (a. a. 0.) lesen wir: „Das Geld liefert den gemeinsamen Werthmesser für alles, weil alles nach Geld gemessen wird", daher auch sein Name "vóuroux, weil es seine Geltung und seinen Werth nicht von der Natur, sondern durch das geltende Gesetz (vónos) hat, und weil es in unserer Macht steht, dasselbe zu verändern und unbrauchbar zu machen".

Es kann aber aus eben diesem von Aristoteles angeführten Grunde das Geld nicht das letzte werthbestimmende Element in den

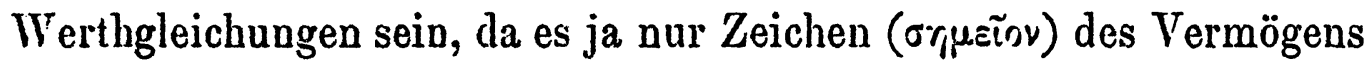
ist und nur die Rolle spielt, die Vergleichung und den Austausch der Dinge zu erleichtern und zu repräsentiren.

Es muss in den gewertheten Dingen selbst etwas Gleiches vorkommen - dessen war sich Aristoteles sehr wohl bewusst und hat es bei dem eben Angeführten nicht bewenden lassen, wie ihm Marx (Kap. I' S. 26) vorwifft, wenn er sagt, dass er hier "gestutzt und lie weitere Analyse der Werthformen aufgegeben habe", dass nach ihm jene „Gleichsetzung nur etwas der wahren Natur der Dinge Fremdes, also nur ,Nothbehelf des practischen Bedürfnisses' " sein könne, kurz, dass er nicht in den verschiedenen Tauschgegenständen das Gleiche - "die menschliche Arbeit" entdeckt habe; und das habe Aristoteles ,aus der Werthform selbst" nicht herauszulesen vermocht, weil die griechische Gesellschaft auf der Sklavenarbeit beruhte, dalier dio Engleichlieit der Menschen und ihrer Arbeitskräfte zur Basis batte".

Beschen wir uns die diesbezüglichen Stellen bei Aristoteles etwas näher, so finden wir darin wohl mehr, als Marx gefunden hat.

Sachden Aristoteles im V. Buche der Ethik im allgemeinen

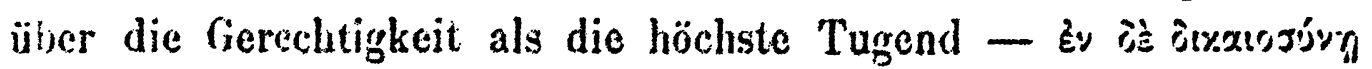

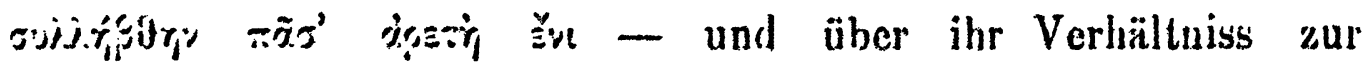


Tugond als Gattung - „Tugend ist die vorsätzliche Fertigkeit, welche in unseren subjectiven Trieben und Neigungen die Mitto hält, bestimmt durch die Vernunft und in der Art und Woise, wie sie der vernünftige Mann bestimmt" (Eth. II. 6) - vorausgeschickt hat, wonach die Gerechtigkeit jene Tugend ist, welche die Beziehungen $\mathrm{zu}$ den Mitmenschen regelt, kommt er im 8. Kapitel auf die gesellschaftlichen Verkehrsverhältpisse und den Tausch zu sprechen, wobei die „wiedervergeltende Gerechtigkeit, bei der auf das qualitative Verbältnis und nicht auf die quantitative

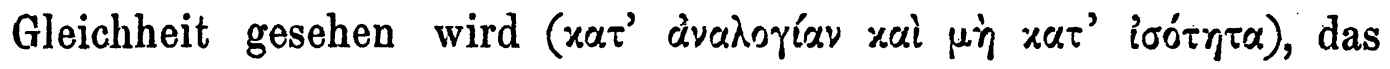
zusammenhängende Band bildet; denu dadurch, dass jedem seine Handlungen verhältnissmässig erwidert werden, wird die staatsbürgerliche Gesellschaft zusammengehalten ... und es ist die

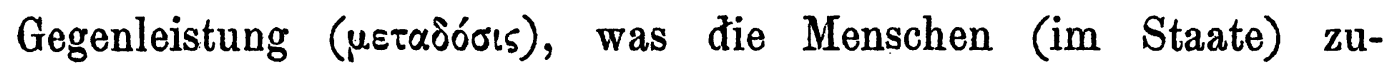
sammenhält."

Nun folgt eine eingehende Analyse dieser ,Gegenleistungen nach

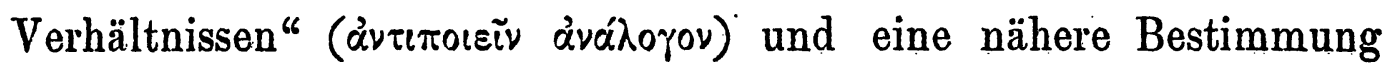
dieser Verhältnisse:

„Zustande gebracht wird diese gegenseitige Mittheilung, welche durch Verhältniss ausgeglichen wird, durch die gegenseitige Beziehung aufeinander, die wir uns durch die Figur eines Viereckes vorstellen mögen, dessen gegenüberstehende Winkel durch eine Diagonale verbunden werden: z. B. sei A Baumeister, B Schuster, C Haus, D Schuh. Nun soll also der Baumeister vom Schuster dessen Arbeit (Ëprov) erhalten, und ihm dafür selbst wieder seine Arbeit liefern. Dies wird geschehen können, wenn zuerst ein Verhältniss gefunden ist, nach welchem Schuhe mit einem Hause a usgeglichen werden können, und dann zweitens nach diesem Verhältniss der eine soviel empfängt, als er dem anderen giebt. Geschieht dies nicht, so findet keine Gleichheit (loov) (zwischen Geben und Empfangen) statt, und der Verkehr kann nicht bestehen; denn es ist ja sehr wohl denkbar, dass die Arbeit des einen werth-

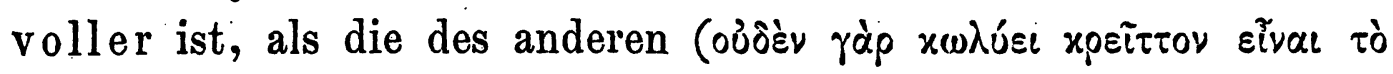

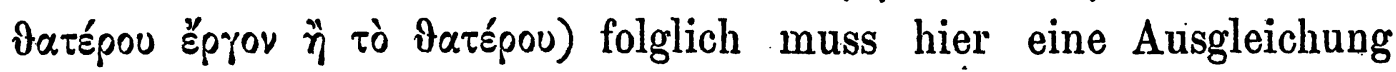
stattfinden."

„Dasselbe ist auch bei anderen Künsten der Fall. Sie würden 
aufgehoben werden, wenn nicht das Wirkende etwas schaffte und loistete, was einen bestimmten quantitativen und qualitativen Werth hat, und wenn nicht der die Leistung Empfangende dies Bestimmte, Soundsovielwerthe und Soundsobeschaffene empfinge. Denn aus zwei Aerzten wird keine Gemeinschaft, wohl aber aus Arzt und Feldbauer, und überhaupt aus Menschen, die in Lebensthätigkeit verschieden und nicht gleich sind, die dann aber eben miteinander ausgeglichen werden müssen."

„Deswregen müssen alle Dinge, die untereinander ausgetauscht werden können und sollen, auf gewisse Weise miteinander vergleichbar sein; und dazu ist das Geld eingeführt worden, und wird gewissermassen zum Vermittler. Denn es misst alles und bestimmt sonach auch, um wieviel die eine Sache die andere an Werth übertrifft oder ihr nachsteht, wie viel Schuhe z. B. gleich sind dem Werthe eines Hauses oder der Beköstigung eines Menschen. Es muss also hier wieder eine Proportion ${ }^{8}$ ) beobachtet werden, nämlich, wie sich der Baumeister oder Feldbauer zum Schuster verhält, soviel Paar Schuhe stehen im richtigen Verhältnisse zu

7) Oben c. 6 hiess es: „Das Gerechte ist ein Proportionalbegriff. Das Proportionale findet nämlich nicht bloss und allein im Gebiete der unbenannten, aus Einheiten bestehenden $Z$ ahl statt, sondern bei aller zählbaren Grösse überhaupt. Die Proportion ist nämlich Gleichhcit von Verhältnissen und bann nicht weniger als vier Gilieder haben. . . . So setzt denn auch das Gerechte mindestens vier Stücke voraus, und das Verhältniss ist dasselbe, denn die Personen, für welche etwas gerecht ist, sind ebenso geschieden, wie die Sachen, um die es sich handelt.

Ilithin wird es hier heissen: wie sich die Person A verhält zur Person B, so verbält sich die Sache $C$ zur Sache $D$; und mithin auch alternirend: wie $A$ zu C, so $B$ zn D. Daraus folgt, dass auch das Ganze zum Ganzen sich verbäl wie dor Theil zum Theile $([A+C]:[B+D]=A: B)$. Und dies eben ist die Verbinlung, welche die Vertheilung macht, und wenn die Zusammenstellung dor Personen und Sachen in dieser Weise geschieht, so geschieht die Verlindung gerecht."

.Somit ist also die Verbiudung des Gliedes $\Lambda$ mit $\mathrm{C}$ und dic des Gliedes B mit I) das distributive Gerechte, und bildet zugleich die Nitte für das, was die Pripistion stirt, denn das Proportionale ist cin Mittleres und das Gerechte hionierlerum ist ein Proportionales. Bs nannten aber solche Proportin die Jathematiker eine geometrische, denn bei der trifft es $\% u$, dass das eine Ganze zu dem anderen sich verhält wie das eine Verhältnissuglicd zu den anderen. . Itsn: das Fere but ist dies Verhälnissmässige, das Unge- 
einem Hause, oder zu dem Werthe der Beköstigung eines Menschen. 1)enn wïre es nicht möglich, so würde auch kein Tauschverkehr

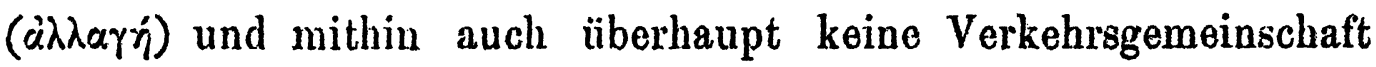
(rotvervía) möglich sein. - Es wird aber dies nicht möglich sein, wenn jene Dinge nicht in irgend einer Weise gleich wären. Folglich ist es eine Nothwendigkeit, dass es, wie schon gesagt, etwas Einheitliches giebt, wodurch alle Dinge gemessen werden. Jies ist aber im wahren und eigentlichen Sinne das Be-

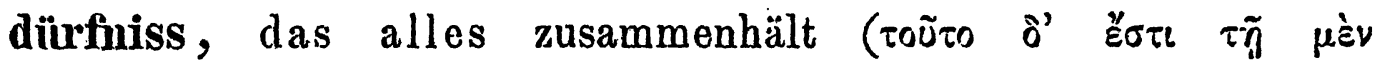

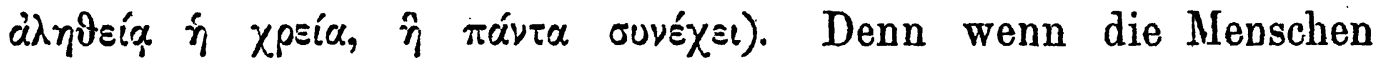
nichts nöthig hätten, oder nicht gleichmässig Bedürfnisse hätten,

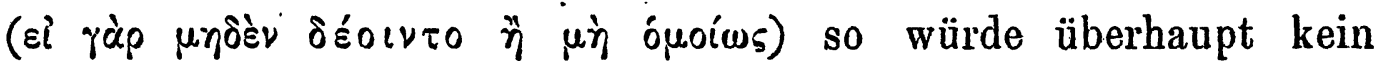
Austauschverkehr, oder doch kein gegenseitiger stattfinden. So aber ist als Stellvertreter des Bedürfnisses das Geld eingetreten nach allgemeiner Uebereinkunft, und darum führt es auch den Namen vó $\mu\llcorner\sigma \mu \alpha$, weil es seine Geltung und seinen Werth nicht von der Natur, sondern durch das geltende Gesetz (vóuos) hat, und weil es in unserer Macht steht, es zu verändern und unbrauchbar zu machen."

"Sonach wird nun also das Verhältniss der Wiedervergeltung stattfinden, wenn die Ausgleichung eingetreten ist, sodass, wie sich der Feldbauer zum Schuster, so das Werk des Schusters zu dem Erzeugniss des Feldbauers verhält. Sobald diese beiden ihre Arbeit untereinander auszutauschen haben, muss man sie in die Form einer Proportion bringen; geschieht dies nicht, so wird beiderlei Uebergewicht auf einer Seite sein. Vielmehr nur dann, wenn sie erhalten, was ihnen zukommt, nur dann werden sie Gleiche und miteinander gemeinsam Verkehrende sein, weil die Möglichkeit vorhanden ist, diese Gleichheit unter ihnen herzustellen. Ist der Feldbauer A und die Beköstigung C, so ist der Schuster B und

rechte dagegen ist das, was diesem Verhältnisse zuwiderläuft. Es wird alsdann ein Glied im Verhältnisse zu gross, das andere zu klein, und dies zeigt sich auch bei den wirklichen Handlungen: der nämlich, welcher Unrecht thut, masst sich von dem Gute, um das es sich handelt, $z u$ viel an, während der Unrecht Leidende davon zu wenig erhält. .." 
seine Arbeit, die ausgeglichene D. Wäre diese Wiedervergeltung nicht möglich, so gïbe es keine Verkehrsgemeinschaft."

„Dass es aber das Bedürfniss ist, was wie ein Band die Menschen zusammenhält, ergiebt sich daraus, dass, weun zwei Personen oder Völkerschaften nicht, entweder beide zugleich oder doch die eine, in der Lage des gegenseitigen Bedürfnisses sind, sie nicht mit einander Tauschverkehr treiben, wie das geschieht, wenn der eine Theil hat, was ein anderer begehrt, z. B. Wein, wofür dann die anderen etwa den Export von Lebensmitteln verstatten. Hier ist nun also eine Ausgleichung nothwendig."

"Was nun aber den Fall eines Tausches anlangt, dessen Bedürfuiss vielleicht später eintritt, wenn es auch im gegenwärtigen Augenblicke nicht vorhanden ist, so tritt für dessen Möglichkeit uns das Geld gleichsam als Bürge ein. Deun wer dies bringt, muss erhalten können, - was er wünscht und bedarf. Allerdings ist auch das Geld denselben Werthmodificationen unterworfen, weil es nicht immer gleichviel gilt; allein es soll doch der Absicht nach vorzugsweise ein ständiger Werthmesser sein. Darum muss alles nach ihm abgeschätzt sein, weil so immer Austausch und somit Verkebragemeinschaft möglich ist. Das Geld also, weil es gleichsam ein Ylass ist, welches. für die verschiedenen Dinge einen gleichen Massstab liefert, gleicht aus. Denn sowie es keine Verkehrsgemeinschaft geben würde ohne Austausch und keinen Austausch, wenn keine Gleichheit herzustellen wäre, so wäre auch keine Gleichheit möglich, wenn es keinen Massstab gäbe. Genau genommen ist es freilich unmöglich, dass Dinge, die so sehr von einander verschieden sind, in Wirklichkeit commensurabel werden können, allein in Bezug auf das Bedürfnis ist es gar wohl möglich.

Fs muss also, wie gesagt, ein bestimmter gemeinsamer Nassstab da sein, und zwar ein durch Cebereinkunft als geltend festgesetzter, der deshalb auch Geld (vífugux) heisst, denn das Geld liefert den gemeinsamen Werthmassstab für alles, weil alles nach Geld gemesseu wird. Sei A ein Haus, B 10 Minen, $C$ ein Bett. Nun

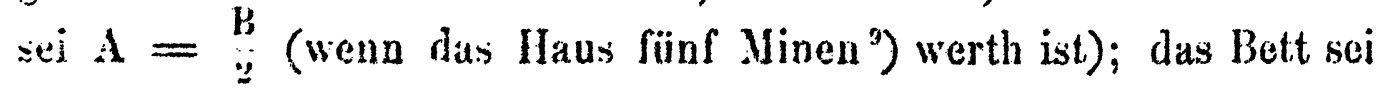


der zohnte Theil von B: so ergiebt sich, wie viele Betten gleich sind einem Hause, nämlich fünf. Offenbar war dies auch die Art und Weise, wie zuerst der Austausch geschah, ehe es Geld gab; denn cs ist kein Unterschied, ob man fünf Betten für ein Haus giebt, oder den Geldwerth der fünf Betten."

Das ist die aristotelische ${ }^{10}$ ) Werthanalyse in Wirklichkeit.

Was also den Dingen einen Werth gibt, ist ihre Beziehung zu

10) Wie Marx, so hat aber auch Wenckstern selbst sogar bei der Vertheidigung Aristoteles' in diesem zu wenig gefunden; in "Marx" heisst es (S. 151): "Als Naturforscher und Philosophen konnten dem Aristoteles Dinge ganz verschiedener Art, incommensurable Dinge denkbar sein. Die Schranke des philosophischen und naturwissenschaftlichen Denkens des Aristoteles, welcher noch nicht mit den Gesetzen der Causalität, der im Effect messbaren Causalität, der Erhaltung der Kraft, der Entwicklung der Formen vertraut war, verhinderte Aristoteles zu erkennen, dass Dinge ganz verschiedener Art auch philosophisch und naturwissenschaftlich, sowie sie nur unter. bestimmte Fragestellung gebracht werden, commensurabel sind. Der Philosoph und Naturforscher Aristoteles ist für diesen Mangel an Tiefe verantwortlich zu machen. ..“

Auf diesen Vorwurf hin ist zu erwidern, dass Aristoteles sowohl das Causalgesetz, als auch das Prinzip der Erhaltung der Energie und Entwicklung der Formen kennt.

Der Causalsatz „keine Wirkung ohne Ursache“ ist bei Aristoteles sogar ein Axiom, indem „Wirkung“ und "Ursache" bei ihm correlative Bègriffe sind (vgl. Met. $\alpha, 3,984$ a 21); ist ihm doch die deductive Wissenschaft als „Erkenntniss der Dinge durch deren Ursachen“. das Ideal der Wissenschaft.

Dass das Energiegesetz den Alten bekannt war, wenn auch nicht in der exacten Form, wie wir es seit der Entdeckung des mechanischen Wärmeäquivalents durch R. Mayer 1842 kennen, haben schon Physiker nachgewiesen (Rühlmann, Verdet, Heller etc.); nicht umsonst hat Fourier als Motto seiner "Theorie analitique de la chaleur" den Satz Platos verwendet: „Et ignem regunt numeri“. R. Nayer selbst beruft sich bei seinen theoretischen Ausführungen der mechanischen Wärmelehre unausgesetzt auf aristotelisch= scholastische Sätre,(z. B. causa aequat effectum), während er von der modernen deutschen Philosophie nichts zu verstehen vorgibt. (S. seine „Mechanik der Wärme," hgg. v. Weyrauch, 1893.)

Ebenso wurden aber auch die Elemente der Evolutionstheorie bei den Alten (Heraklit, Aristoteles) aufgespürt. Es sei nur auf die Schrift Lewes' "Aristoteles" verwiesen, welcher Autor sicher nicht zu den blinden Verehrern des alten Philosophen zu rechnen ist.

Wie „Dinge ganz verschiedener Art" nach Aristoteles commensurabel sein können, beweist seine „Metaphysik“, die man nicht übersehen darf. 
den menschlichen Bedürfnissen, zum Gebrauch, zum gesellschaftlichen Leben; ein Ding wird umso höher gewerthet, je mehr es dazu dient, ein brennendes Bedürfniss zu befriedigen. Die Eigenschaft der Dinge, gesellschaftliche Bedürfnisse - also nicht die des Producenten, sondern eines anderen -, zu befriedigen, ist ihr Werth ${ }^{11}$ ) (T'auschwert). Und so sind die Dinge als Gebrauchsgegenstände commensurabel und vergleichbar.

Eine nähere Analyse der Bedürfnissbefriedigung, und welche einzelnen Momente auf die Bestimmung des Preises (wirklichen Tauschwerthes) eineu Einfluss ausüben, ist ausdrücklich und explicite in Aristoteles nicht enthalten; dieser giebt zwar, un die Nothwendigkeit der Commensurabilität der Waaren (Tauschgüter) zu betonen, das Beispiel: „Wie sich der Baumeister zum Schuster verhält, soviele Paar Schuhe stehen im richtigen Verhältnisse zu einem Hause". Allein wie verhält sich der Baumeister zum Schuster? Warum ist „die Arbeit des einen werthvoller als die des anderen“? lst das Bedürfniss nach den Werken des Baumeisters grösser als nach denen des Schusters? Das untersucht genauer unser Philosoph nicht; er begnügt sich mit der gegebenen Thatsache, dass der Baumeister über dem Schuster steht und in Folge dessen seine Arbeit werthvoller ist als die des Letzteren, „denn eine bessere Leistung (Ëprov) ist immer die, welche von Besseren zustande gebracht wird." (Polit. I. 5.)

Die ökonomische Ausgleichung in einer auf Güter- Tauschund Nittheilung beruhenden, Waaren producirenden Gesellschaft kann nur möglich sein, wenn Vergleichbarkeit und Gleichheit der menschlichen Arbeit angenommen wird; sonst wäre eine Vergleichung der Kunst und Arbeit des Baumeisters mit jener des Schusters oder Bauern unmöglich. So aber ist beiden gemein die Eigenschaft, Producte herzustellen, welche gesellschaftliche Bedürfnisse befriedigen. „Dieses Princip (der Ausgleichung) findet auch bei allen Künsten und Verrichtungen statt; denn sie wïrden sich gegenseitig aufheben, wenn nicht die Kraft und Geschicklichkeit, die etwas hervorbringt, damit zugleich ein 
quantitaliv und qualitativ Abschätzbares hervorbrächte, und der Theil, der dessen bedarf, gerade dies und gerade soviel und gcrade ein solches bedürfte" (Eth. V. 7).

So betont wohl Aristoteles, dass in der Ausgleichung der

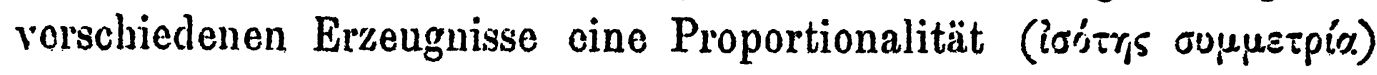
vorhanden sein müsse, damit Gerechtigkeit herrsche; aber schliesslich bleibt. er bei der historisch gegebenen Bewerthung stehen, welche bei verschiedenen Menschen and in verschiedenen Ver-

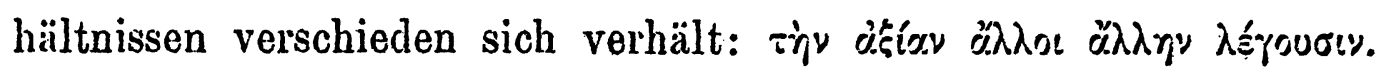

Etwas weiter und tiefér ist hierin Aristoteles' grosser Schüler gelangt; zwar ist das Schlussresultat seiner diesbezüglichen Untersuchungen der Satz, dass sich jene Werthgleichungen nicht mit mathematischer Genauigkeit, sondern nur nach ungefährer Schätzung bestimmen lassen ${ }^{12}$ ). Doch giebt Thomas zu den obigen Ausführungen einen Commentar, aus dem leicht entnommen wird, dass er einige Momente gesehen, die von Aristoteles nicht ausdrücklich erwähnt werden.

Während Aristoteles nur die Behauptung hinstellt, dass der Baumeister den Schuster übertrifft, giebt Thomas eine nähere Bestimmung hinzu: er übertrifft ihn in Folge seiner Arbeitsleistung (in labore) und in Folge der bei seinen Arbeiten geforderten und in ihnen verkörperten $\mathrm{K}$ osten (in expensis) ${ }^{13}$ ).

Es sind in dieser Bewerthung der Gegenstände zwei Momente ausdrücklich hervorgehoben: erstens die zur Erzeugung derselben nothwendige Arbeit, zweitens, die aufgewendeten Kosten und gebrachten Opfer. Je mehr und je grösser Werthe (Capital) geheischt werden, umso theuerer, werthvoller ist die Sache: das Bedürfniss nach einer solchen Sache - so glauben wir im aristotelischen Sinne consequent und explicite weiter ausführen zu können - wird nicht so leicht befriedigt, daher subjectiv als besonders gross empfunden,

12) Justum pretium rerum non est punctualiter determinatum, sed magis in quadam aestimatione consistit, ita quod modica additio vel minutio non videtur tollere aequalitatem iustitiae (summa theologica 2. 2. q. 77 a 1 ad 1).

13) Ut sit iusta commutatio, oportet, ut tanta calciamenta dentur pro una domo, quantum aedificator excedit coriarium in labore et in expensis (Comment. in Ethic. 1. V. lect. 9). 
weil die Sache schwer erhältlich, selten ist; und die Seltenheit ist ein anderes Moment bei der nationalökonomischen Wertbbestimmung, auf welches Thomas bei der Besprechung des Goldgeldes hinweist, welches nach ihm wegen seines seltenen Vorkommens einen grossen Werth hat: modicum de istis (metallis) propter eorum raritatem valebat multum de aliis rebus.

Das Metallgeld hat nach Aristoteles und Thomas einen melnfachen Vorzug; das (Edel-) Metall hat in sich einen Werth, indem es schön und glänzend ist, daher unsere ästhetischen Bedürfnisse befriedigt, und indem es practischen Nutzen gewïhren kann; es kommt ferner nicht häufig vor, ein Umstand, der den Werth hebt, und ist leicht transportirbar. -

Bei der Werthbestimmung, um kurz zu wiederholen, unterscheiden Aristoteles und Thomas folgende Momente: Bedürfniss Nützlichkeit, Arbeit, Kosten, Seltenheit.

Der Fundamentalbegriff unter diesen ist das "Bedürfniss". Oekonomischen Werth haben heisst gesellschaftliche Bedürfnisse zu befriedigen im Stande sein.

Ist das Bedürfniss gegeben, so kommen andere minder wichtige Nomente in Betracht; soll das Bedürfniss dasjenige sein, „wodurch alles gemessen wird" und "das alles zusammenhält", so müssen sich im aristotelischen Sinne alle diese Momentc auf dasselbe zurückführen lassen, was wir versuchen wollen; so die Nützlichkeit; je stärker und wichtiger das Bedürfniss nach einem Dinge, um so grösser ist in der Volkssprache seine Nützlichkeit. Arbeit, Kosten und Seltenheit lassen sich auf einen Begriff, nnd dieser hinwiederum auf das Bedürfniss reduciren: je mehr menschliche Arbeit und Opfer (Kosten) die Verfertigang eines Gebrauchsgegenstandes voraussetzt, als ein um so seltenerer - weil schwerer erhïltlich - erscheint er, und umsomehr wird das Bedürfniss nach ihm subjectiv empfunden. Der Baumeister repräsentirt viel geistige und physische Arbeitsenergie, seine Bildung erfordert viele Kosten. in Folge dessen sind guto Baumeister solten, daher wertholl oder theuer. Eine Sache, die gewöhnlich in der Tauschwirtschaft werthlos ist, wie das Wasser, kann unter Umstinden (in der Wüste) in Folge des seltenen Vorkommens cinen hohen Werth 
erhalten, weil das Bedürfniss darnach schwiorig befriedigt wird und daher st:ïker auftritt.

Entscheidend in jodem Falle ist nach Aristoteles das Bedürfniss; jo stärker und dringender das Bedürfniss nach einer Sache - in welcher Art immer - um so grösser ihr Werth. Res differentes commensurantur per comparationem ad indige n tiam hominum et continentur sub una mensura nummi (Comment. in Eth. V. lect. 9).

Der Tauschhandel ist nach Aristoteles, insoferne sich derselbe auf unentbehrliche Gebrauchsgegenstände bezieht, in einer gegliederten Gesellschaft nothwendig und besteht, wie schon gesagt, darin, eigene Producte gegen fremde, deren man bedarf, und die man nicht besitzt, einzutauschen. Das ist der natürliche

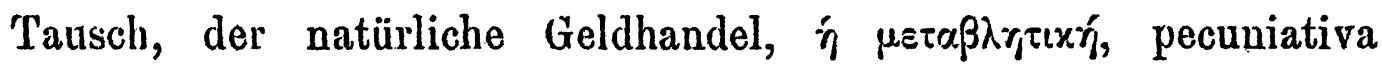
naturalis ${ }^{14}$ ).

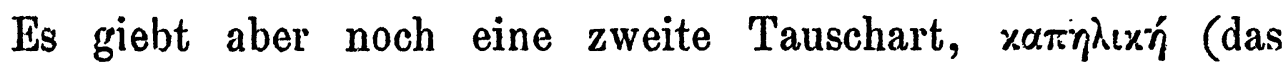
eigentliche Geldgeschäft), deren wahrer Zweck keineswegs darin besteht, nothwendige Gebrauchsgegenstïnde zu verschaffen, sondern darin, das Geld (Capital), welches Repräsentant für alle Gebrauchswerthe ist, zu vermehren: man will gewinnen ${ }^{15}$ ). „Die Benennungen Schaden und Gewinn (xépôos, lucrum) kommen eigentlich her vom freiwilligen Tausche. Mehr erhalten, als man vorher hatte, heisst nämlich gewinnen (profitiren), und weniger haben, als man zuvor besass, heisst Schaden haben, wie das beim Kaufen und Verkaufen und bei allen solchen Verkehrgeschäften vorkommt, die das Gesetz erlaubt" (Eth. V. 7.) Solcher Gewinn scheint vielen der Hauptzweck der Erwerbskunst überhaupt, ja manchen sogar der Endzweck der Politik und Oekonomik zu sein.

Dies ist jedoch nach den Anschauungen Aristoteles' und 'Thomas' unrichtig; eine derartige Erwerbs- und Bereicherungskunst

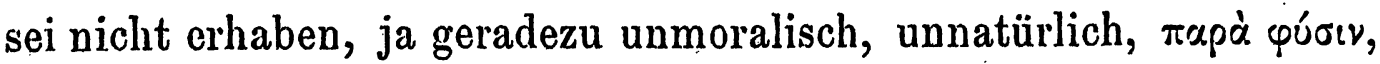

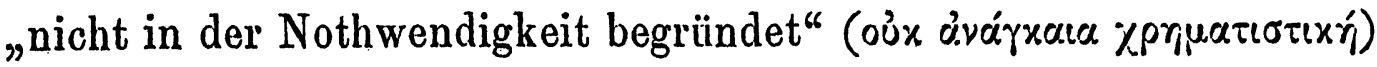
non necessaria; denn das heisse, das letate Ziel der Wünsche in

14) Die Circulation der Waare und des Geldes, wie es Marx darzustellen pflegt, ist: W-G-W.

15) Die Circulation ist: G-W-G. 
das Geld und den Reichthum zu setzen, welche doch nur Mittel zum Zwecke und nicht höchste Zwecke sein könnten, und unnatürlich sei es, dass das Geld, welches ja an sich keinen eigentlichen Werth habe, sondern nur in Folge gegenseitiger Uebereinkunft einen darstelle, Gewinn trage. „Mit dem grössten Recht ist das Zins-

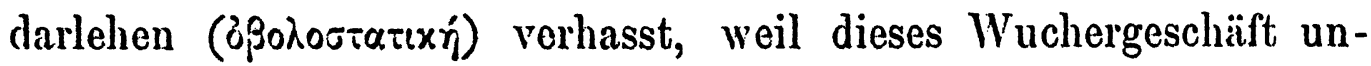
mittelbar aus dem Geld selber den Erwerb rieht und nicht aus dem, wofür das Geld doch allein erfunden ist. Denn nur zur Erleichterung des Tausches kam es auf, der Zins aber vermehrt es an sich selber. Daher denn auch der griechische Name für "Zins" soviel als „Junges" (tóxos von tíxic) bedeutet, denn das Junge pflegt seinen Erzengern ähnlich zu sein, und so ist auch der Zins wieder Geld vom Gelde, und diese Art von Erwerbskunst ist denn hiernach die widernatürlichste von allen ${ }^{616}$ ) (Polit. I. 10).

19) Wir citieren die betreffenden höchst wichtigen Stellen aus der Politik (I. 5,9$): \ldots$... Die eine Art von Erwerbskunst ist naturgemäss ein Theil der IIausbaltungskunst (oi\%ovopex $\eta$ ), diejenige nämlich, deren Aufgabe es ist, einen Vorrath von Gegenständen zu sammeln, die nothwendig zum Leben und nützlich für die staatliche und bäusliche Gemeinschaft sind ..... und der wahre Reichthum besteht, wie es scheint, in ihnen. Denn das zu einem zreckentsprechenden Leben genügende Maass eines solchen Besitzes geht nicht ins Unendliche, und ron ibm gilt nicht, was Solon dichteto:

Reichthum hat kein Ziel, das kennbar den Menschen gesteckt ist.

Vielmehr hier ist wohl ein solches gesteckt gerade wie bei den Mitteln aller anderen $\mathbf{K}$ ünste. Denn in keiner einzigen Kunst giebt es Werkzeuge, denen die Cnendlichbeit zukāme weder an Menge noch an Grösse, der Reichthum aber ist eben nichts anderes als der erforderliche Vorrath von Mitteln und Werkzeugen für die Haus- und Staatsverwaltung.

Also, dass auf eine gewisse Erwerbskunst die Hausverwalter und Staatsmänner von Natur angewiesen sind, und aus welchem Grunde dies der Fall ist, das ist blar. Aber es giebt auch eine andere Art von Erwerbskunst, welche uan vorzugsweise und mit Recht die Bereicherungskunst nennt, und sie ist es. welche die Schuld daran trägt, dass es für Reichthum und liesitz nicht Jaass und $Z$ iel $z$ a geben scheint, und viele halten sie für eine und dieselbe mit jener ersteren wegen der allerdings naben Verwandtschaft. mit ihr. In Wahrheit aber ist sie doch trotzdem, dass sie ibr nicht ferne steht, keineswegs: einerlei mit ihr. Denn whatend jene ein Werk der Natur isl, ist e; lieve nicht, sondern vielmehr ein Werk ler Kunst und der Velunng. Jehmen wir nun für iture Betrachtung folgenden Ausgangsjounkt. Dio Benutzung eines jeden Besitzthumes ist eine doppelte ... F Forlsetzung $\Lambda \mathrm{n}$ merkung 6;.] l'nd als nun so aus deun unentbelirlichen Hedürfuiss des 
Es ist dem 7u Folge nach Aristoteles (und Thomas) jener Theil der Erwerbskunde und der im Tauschhandel bestehenden Bereicherungskunst, welcher auf einer Vermehrung der natürlichen

Tausches einmal das Gold [s. S. 414] hervorgegangen war, da bildete sich jene andere Art der Erwerbskunst, das eigentliche Handels- und Geldgeschäft (тò $x \alpha \pi \eta \eta \lambda(\%, y)$, anfünglich wahrscheinlich in sebr einfacher Art, bereits bald aber durch die Uebung in künstlicherer Weise darauf gerichtet, wie und mit welchen Mitteln man beim Umsatz möglichst viel Gewinn machen könnte. Und daraus entsteht dann der Schein, als wäre die Erwerbskunst vorzugsweise auf das Geld gerichtet und die Aufgabe derselben, dass

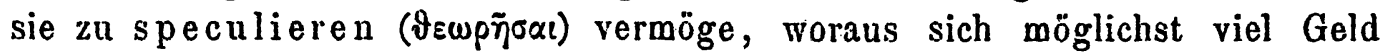
zichen lasse, soferne sie ja in der That Reichthum und Vermögen scbafft. Wohl setzt man auch den Reichthum insgemein in die Masse von möglichst viel Geld, und so entsteht dann der Glaube, dass die Erwerbskunst es hiemit $z u$ thun habe und in eigentlichen Handels- und Geldgeschäfte bestehe.

Dann hört man indessen von anderer Seite auch wieder, mit dem Gelde sei es nichts als leeres Gerede, und es sei schlechterdings ein Erzeugnis willkürlicher Satzung und von Natur gar nichts, weil, sobald eine Münzveränderung vorgenommen ist, es nichts mehr werth (oủovòs äsıov) und zu keinem der nothwendigen Lebensbedürfnisse nütze sei, und weil es einem, der Geld im Ueberflusse habe, doch oft an den nothwendigen Lebensmitteln fehlen könne, und es denn doch widersinnig sei, dass dasjenige Reichthum sein sollte, in dessen Yollbesitz einer Hungers sterben könne, wie von jenem Midas die Sage geht, indem ihm in Erfüllung seiner unersättlichen Wünsche alles ihni Vorgesetzte zu Golde wurde. Und so suchen dann die Vertreter dieser Ansicht in. etwas anderem das wahre Wesen des Reichthums und der Erwerbskunde, und sie thun recht daran. Denn in etwas anderem besteht ja in der. That der natürliche Reichthum und die natürliche Erwerbskunst, und nur diese letztere ist die zur Haushaltungskunde gehörige, während die künstliche im eigentlichen Handelsgeschäft besteht, indem sie nicht auf den Vermögenserwerb schlechthin, sondern auf den Vermögensumsatz gerichtet ist*). Und diese hat es augenscheinlich mit dem Gelde zu thun, denn das Geld ist beim Handel Anfang und Ende. Darum auch ist ohne Ziel und Grenze der Reichthum, welcher durch diese Art von Erwerbskunst erzengt wird. Denn wie die Heillkunst kein Maass und keine Grenze hat, bis zu denen sie allein die Erzeugung der Gesundheit ausdehmen darf, und wie überhaupt für jede Kunst ihr Zweck und Ziel eine unendliche Aufgabe ist, auf deren möglichste Erfüllung sie eben nur hinstreben kann, während für die Mittel das Unendliche nicht bestimmend ist, weil hier vielmehr der Zweck eben Grenze und Ende setzt, so hat auch diese Art von Erwerbskunst in der Verfolgung ihres Zieles und Zweckes keine. Grenze, ihr Ziel und Zweck aber ist eben ein derartiger Reichthum und Ver-

*) Man beachte die lichtrolle Darstellung des Umschlages des Hausvermögens in speculatives Capital. „Im Kerne die ganze moderne Kritik des Kapitals, d. h. die negative Arbeit der socialistischen Theorien!" (Schäffle.) 
Güter, aber nicht auf die endlose Vergrösserung des Capitals durch "Mehrgewinn" und Zinsen gerichtet ist, eine für den Staatshaushalt nothwendige und nützliche Kunst und als solche eine Hilfswissenschaft der Oekonomik und Politik; die wahre Aufgabe der Politik jedoch ist, nicht Reichthümer zu gewinnen und zu vermehren

mögensbesitz; die andere dagegen, welche nur die Mittel für den Haushalt zu schaffen hat, hat eben damit ihre Grenze; denn die Erreichung jenes Zieles nnd $\mathrm{Zweckes}$ ist gar nicht ihre Aufgabe.

Und so ist denn hiernach offenbar, dass von Natur aus aller Reichthum "seine notwendige Grenze hat; allein in der Thatsächlichkeit sehen wir das Gegentheil eintreten; denn alle, welche auf den Erwerb bedacht sind, suchen ihr Geld bis ins Grenzenlose zu vermehren.

Der Grund hierron ist eben die nahe Berührung beider Arten von Erwerbskunst. Denn die Anwendung der einen spielt in die der anderen hinüber, weil es Anwendungen derselben Sache sind, aber Seitens der eineu Erwerbs kunst zu einem anderen $\mathrm{Z}$ wecke, Seitens der anderen bloss zur Besitzvermehrung. lind daher glauben manche, das letztere sei die Aufgabe der IIaushaltungskunst (oixovoulxí) und verharren dabei, dass man das vorhandene hare Geld entweder mindestens zu erhalten oder richtiger noch bis ins Endlose zu vermehren suche.

Die Ersache solcher Denkweise aber liegt darin, dass die meisten Menschen nur um das Leben und nicht um ein vollkommenes Leben sorgen; da uun die Lust zum Leben ins Endlose geht, so trachten sie auch, die Mittel zum Leben bis ins Endlose anzuhäufen. Dic aber, welche nach vollkommenen Leben trachten, haben hierbei meist nur die sinnlichen Genüsse im Auge, und dis mit dem Besitz auch die Jröglichkeit, sich solche zu verschaffen, augensheinlich sich verbindet, so richtet sich ihr ganzes Dichten und Trachten

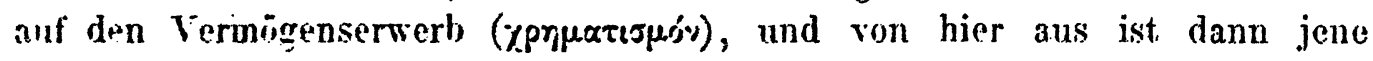
andere (widernatürllche) Art von Erwerlskiunst aufgekommen. Denn jeder Sinnengenuss hängrt am Vebermaass, und so trachten sio denn nach einer Kunst, dir ihnen das Vebermaass dieses Genusses verschaffi, und können sie dissillue durch die Pereichenugskunst nicht errejchen, so jagen sie ihm auf *iurn aubren Wege nach und weuden alle Künste und Fertigkeiten ihrer

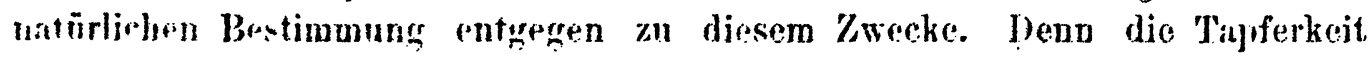
jut nivht dazu da, utn firld, somlem un Heldenmuth zu croeugen, und die Kriors- und Ileilknost hat gleiehfalls nicht jene Bestimmune, sondern die

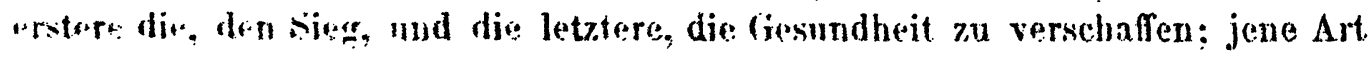

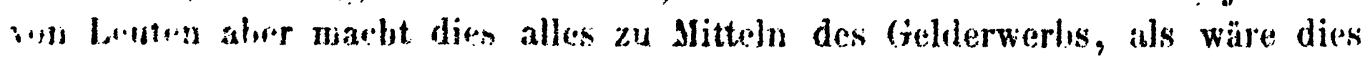
der \%wek (ron allom;, und als yälto es hier, dass doch auf seinen \%weck alle.s hesogen werden müse* $)$.

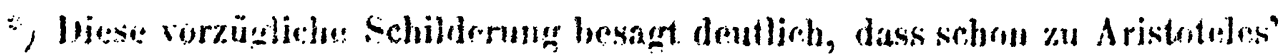

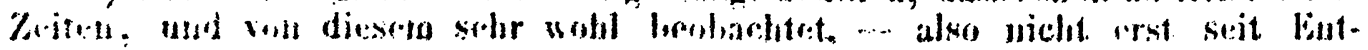

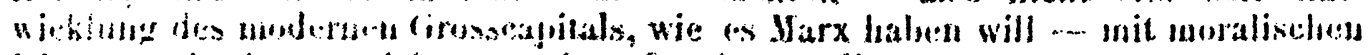

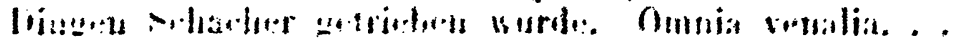

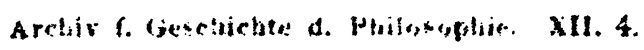


(was Sache der Erwerbskunde ist), sondern die schon durch Nalur gegebenen und durch Kunst gewonnenen Besitzthümer nach dem Princip der Gerechtigkeit unter die Staatsangehörigen zu vertheilen ${ }^{17}$ ). Opus politicae vel oeconomiae proprium non est, acquirere res necessarias, sed dispensare; ad oeconomiam pertinet uti pecunia iam acquisita (Comment. in Polit. 1 I. lect. 8).

Ind so haben wir denn nun auseinandergesetzt, sowohl worin die nicht in der Nothwendigkeit begründete Bereicherungskunst besteht, und woher es gekominen, dass sie (dennoch) bei uns in Brauch ist, als auch in Bezug auf die unentbehrliche erläutert, dass sie verschieden von jener und vielmehr wirklich naturgemäss zur Haushaltung gehörig ist, als auf Herbeischaffung der Nahrung gerichtet, und nicht wie jene ins Endlose geht, sondern Maass und Grenze hat." - - -

"Wenn nun aber die Erwerbskunst, wie gesagt, eine doppelte ist, Theils eine auf den blossen Handelsgewinn, Theils eine auf die Zwecke der Haus haltung berechnete, und nur die letztere nothwendig und löblich ist, die erstere, aus dem blossen Umsatze gezogene dagegen mit Recht getadelt wird, weil sie nicht auf die Natur begründet ist, sondern die Menschen diesen Gewinn von einander ziehen (sich wechselseitig ausbeuten), so ist vollends mit

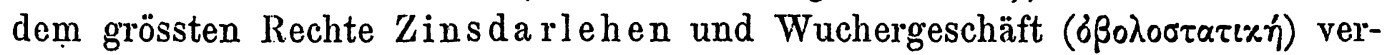
hasst, weil dieses unmittelbar aus dem Gelde selber den Erwerb zieht und nicht aus dem, wofür das Geld doch allein erfunden ist. Denn nur zur Erleichterung des Tausches kam es auf, der Zins aber vermehrt es an sich selber. Daher denn auch der griechische Name für "Zins" soviel als "Junges". bedeutet, denn das Junge pflegt seinen Erzeugern ähnlich zu sein, und so ist auch der Zins wieder Geld vom Gelde. Und diese Art von Erwerbskunst ist denn hiernach die widernatürlichste von allen."

17) "Wie die Staatskunst sich auch die Menschen nicht erst schafft, sondern sie bereits aus den Händen der Natur empfängt und (nur für ihre Zwecke) verwendet, so muss die Natur zum Unterhalt für sie auch Land oder Meer oder sonst was hergeben - sodann aber über diese gegebenen Mittel in angemessener Weise zu verfügen, das (allein) ist es, was dem Haushalter (oikovónos) zukommt. Ist es doch auch nicht die Sache der Weberei, Wolle zu erzeugen, sondern sie zu gebrauchen und zu wissen, was für Wolle gut und tauglich und welche schlecht und untauglich ist. Und nun könnte man doch auch fragen, warum denn gerade die Erwerbskunde ein Theil der Haushaltungskunde sein soll und nicht ebenso gut auch die Heilkunde; denn der Gesundheit sind ja doch die Hausgenossen ebenso bedürftig als des Lebens und der zum Leben nothwendigen Dinge. Es haben denn auch in gewisser Hinsicht der Hausverwalter und Staatsregent wirklich für die Gesundheit zu sorgen, in anderen Fällen dagegen nicht sie, sondern der Arzt. Und so verhält es sich auch Betreffs der Beșitzthümer;' in gewisser Hinsicht haben sich die Hausverwalter darum zu kümmern, in anderer dagegen ist das völlig 
Wir wollen nochmals nach dem Commentar Thomas' zum 1. Buch der Politik (lect. 8) die Erwerbskunde als Hilfsdisciplin der Politik kennzeichnen:

Natürlich und moralisch ist diejenige Erwerbskunde, deren Zweck es ist, Besitzthümer und Geld direct aus den Naturproducten zu gewinnen; unnatürlich, und nur mehr eine Folge der unsittlichen menschlichen Begehrlichkeit und Unmässigkeit ist diejenige, die es lediglich mit der Vermehrung des Geldes aus dem Gelde, mit dem Zinsnehmen zu thun hat.

Thomas nimmt nach Aristoteles folgende Eintheilung der Erwerbskunde vor:

Die Erwerbskunde, pecuniativa, ist:

1. natürlich, wenn Geld und Reichthümer aus den zum Leben nothwendigen Naturproducten gewonnen werden; pecuniativa naturalis: denarii acquiruntur ex rebus naturalibus ad vitam necessariis.

Dieses Gerwinnen geschieht auf doppelte Art;

a) unmittelbar aus den Naturproducten, aus der Bebauung des Bodens (Gewinnung des Weizens, Weins, Oels ....), aus der Viehzucht, dem Bergbau u.s.w.; das ist die eigentliche naturgemässe Erwerbskunde; hierher gehört auch die Tohnarbeit der Handwerker und Taglöhner, mercenaria;

B) aus dem Tausche, sodass Producte in Gegenden angckauft werden, wo ein Ueberfluss an solchen, - daher Angebot, - vorhanden ist, und dann in Orten verkauft werden, wo an solchen Mangel - daher Nachfrage - herrscht; hier spielt schon die Speculation (ikewprijox, considerare), bestehend namentlich in der Voraussicht der Preis-

Sarhe einer Ilifonissenschaft der Hanshaltungrskunde (uämlich der Erwerlsskuturl, Vor allem aber touss hier, wie vorhin gesagt, die Natur selber deu "rford.rlichen stoff bereits grewähren; denn ihr liegt es oh, dem, was sie erzunt hat, aubli den lenterhalt zu geben, wie denn für ein jedes neugeborene

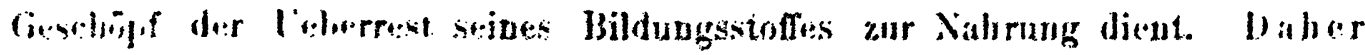

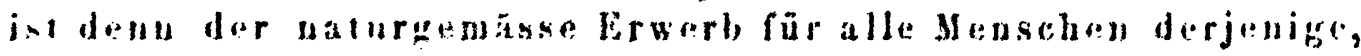

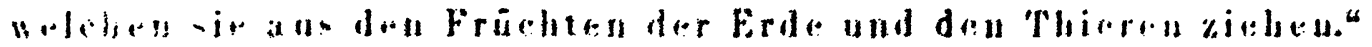


änderung, eine grosse Rolle; diese Bereicherungsart wird von Thomas campsoria (Wechselkunde), nummularia (Geldkunde), oder auch, weil ihr Wesen auf dem Tausche berulit, translativa genannt.

Diese translativa an sich ist nach Thomas nicht tadelnswerth; der Handel (See-, Binnen- und Kram-Handel) ist sogar nothwendig; nur sind factisç die hierbei vorkommenden Ausartungen so unmoralisch, dass bei Thomas, wie auch Aristoteles, der Tauschhandel zumeist zur

2. unnatürlichen, auf der menschlichen Begehrlichkeit beruhenden Bereicherungskunst, die blind lediglich auf die Vermehrung des Geldes ausgeht, hinzugerechnet wird.

Entschieden unnatürlich, verdammens- und hassenswürdig aber ist das Zinsnehmen und Wuchergeschäft, feneratio, quae per usuras pecuniam facit.

Wir sehen, dass Thomas eine Trennung und Scheidung der verschiedenen Erwerbs- und Bereicherungs-Arten vornimmt, ähnlich wie Aristoteles, nur noch schärfer und klarer.

Allein was ist das Kriterium, das ihm die eine Erwerbsart als natürlich, gut und moralisch, die andere als widernatürlich, schlecht und hassenswürdig erscheinen lässt?

Darauf kann man nur antworten: die ethischen Principien.

Der Endzweck des Menschen nach Aristoteles und Thomas ist, sein Leben möglichst zu vervollkommnen, alle seine Kräfte und Fähigkeiten, vor allem die ihm specifisch eigenthü̈mlichen des Verstandes und Willens zur möglichst grossen Entfaltung zu bringen, in deren Genuss das menschliche Glück (sủôauovía) besteht. Nach diesem Glücke hat der Mensch das unwiderstehliche Verlangen, sagen wir, Bedürfniss; die allseitige Vollendung der physischen und geistigen Kräfte ist der grösste Schatz des Menschen. Beide Philosophen bewerthen darum die zur Beschaffung der verschiedenen Bedürfnissbefriedigungsmittel nothwendigen menschlichen Arbeiten und Künste - und daher auch die Gegenstände, die durch solche Arbeiten erzeugt werden, nach der Qualität und Quantität der auf dieselben verwendeten Kräfte. Eine Ar- 
beit hat wenig Werth, zu welcher wenig Voraussicht und Vernunftberechnung verlangt wird, wie die mechanische Taglöhnerarbeit (operationes viles, in quibus parum praevisionum rationis, sed fortuna); "die verächtlichsten sind diejenigen (Arbeiten), zu denen es am

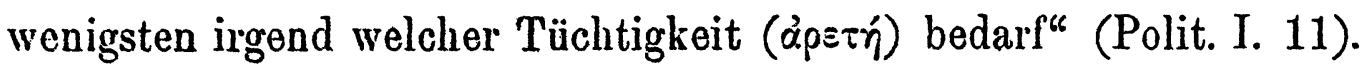
Je mehr und höhere geistige Kräfte verlangt werden, umso höher steht die Leistung; die Arbeit des Handwerkers steht höher als jene des Taglöhners, und so könnte man eine Stufenreihe verschiedener gesellschaftlicher Arbeiten aufstellen. Darum sei es -aber auch für den Philosophen, der sich ausgebildete höhere Kräfte angeeignet, nicht schwer, reich zu werden; Aristoteles führt sinnig das Beispiel von Thales dem Milesier an, der, nachdem man ihm wegen seiner Armuth vorgehalten, "dass doch die Philosophie zu nichts nütze sei", durch kluge Speculation - er hatte in Folge seiner astronomischen Kenntnisse eine reiche Olivenernte vorausgesehen - den Alleinverkauf oder das Monopol der Ernteproducte sich verschafft hat und dadurch, dass er bei starker Nachfrage den Waarenpreis beliebig in die Höhe schrauben konnte, sehr reich geworden ist. Diesem Beispiele fügt Thomas bei: et sic colligens multas pecunias, ostendit, quod philosophis facile est ditari, si volunt, sed non est studium eorum ad hoc: et per hunc modum Thales ostendit suam sapientiam; des Philosophen Streben ist auf Höheres gerichtet.

Von diesem Standpunkte aus hat man auch die Anschauungen Aristoteles' und Thomas' bezüglich der Werthschätzung der 'Thätigkeiten der praktischen Geschäftsleute zu beurtheilen; keinem von beiden ist die Bedeutung der Erwerbskunst entgangen, beide sagen auch, dass der Besitz, grosser Reichthümer im Staatshaushalt geradezu eine Nothwendigkeit ist; ja, Thomas führt ${ }^{1 \times}$ ) sogar aus, dass ein turgendhaftes Leben ohne Vermögensbesitz unmöglich sei und laher die Sorge des Fürsten dem materiellen Wohlstande als der ersten Vorbedingung eines ideellen Gesellschaftslebens zugewandt sein müsse. Si ... status dominorum secundum suam naturam

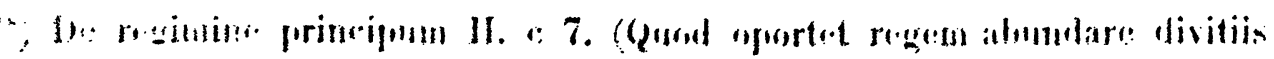

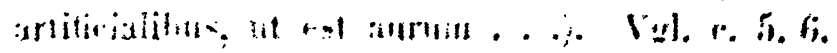


est communicativus: ergo virtus et operatio. Hoc autem esse non potest sine nummismate, sicut nec faber nec carpentarius sine propriis instrumontis. Allein man solle dabei, beim lediglich Materiellen, nicht stehen bleiben, sondern den Reichthum als Voraussetzung für ein menschenwürdiges, höheres Leben erachten.

Das Zinsnehmen, die Erzeugung "des Geldes vom Gelde scheint den beiden allerdings widernatürlich niedrig und hässlich

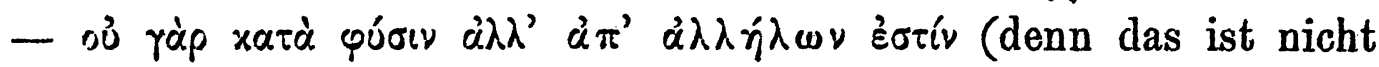
naturgemäss, sondern wechselseitige Ausbeutung), es verstösst gegen die - Gerechtigkeit und Gesinnungsweise der Alten.

Wir wollen nach Thomas ${ }^{19}$ ) Gründe gegen das Zinsnehmon anführen:

Es sind zwei Gattungen von Gebrauchsgegenständen zu unterscheiden: bei den einen ist der Gebrauch (usus) der Sache zugleich deren Consum (consumptio) oder Verbrauch, wie wir den Wein verbrauchen, wenn wir ihn gebrauchen oder trinken; darum darf man bei solchen Gegenständen den Gebrauch der Sache von der Sache selbst nicht trennen; jedem, dem der Gebrauch einer solchen Sache gestattet wird, wird auch dadurch von .selbst die Sache gestattet; wenn daher jemand den Wein, und getrennt davon noch den Gebrauch des Weines verkaufen wollte, so würde er zweimal dieselbe Sache verkaufen, er würde verkaufen, was nicht existirt; und das wäre Unrecht. Ebenso begänge Unrecht, der Wein borgte, und dafür zweifache Vergeltung verlangte: die Rückgabe der gleichen Sache und ferner den Preis für ihre Benützung, den man usura (Leihzins) nennt. Andere Gebrauchsgegenstände dagegen sind der Art, dass ihr Gebrauch nicht zugleich ihr Verbrauch ist, wie die Wohnung; und in dem Falle kann man mit Fug den Gebrauch vom Verbrauch trennen; der Gebrauch des Hauses ist nicht dessen Zerstörung; man kann daher für die Benutzung der Wohnung mit Recht eine Vergütung verlangen, wie es beim sog. Vermiethen geschieht.

Das Geld nun, welches Aristoteles gemäss zur Erleichterung des Tauschverkehrs erfunden wurde, gehört zur ersten Gattung:

19) Summat theologica II. II. q. 78 a 1 c. 
sein Gebrauch ist zugleich sein Verbrauch oder Consum (comsumptio sive distractio), insoferne es für Tanschobjecte verausgabt wird; und darum ist es an und für sich unstatthaft, für den Gebrauch des geliehenen Geldes eine Vergütung zu erlangen, die Zins genannt wird.

So Thomas.

Nochmals aber machen wir aufmerksam, dass weder Aristoteles noch Thomas den Tauschhandel als solchon verdammen, und wenn sich Thomas ähnlich ausdrückt, so hat er einerseits die hiebei "so iippig wuchernden Leidenschaften der concupiscentia, andererseits den Philosophen oder contemplativen Mönch vor Augen, und für einen solchen ist allerdings das gewöhnliche und factische Geschäftsleben nicht angemessen. Den Gegensatz zwischen der ,ausschliesslichen'Natural wirthschaft des Alterthums und Mittelalters, innerhalb welcher die Beiden gelebt, und der Geldwirthschaft der neueren Zeit möchten wir zur Erklärung der nationalökonomischen Grundsätze derselben nicht so hoch veranschlagen, wie man es zumeist thut, zumal ja die Grossindustrie und Geldwirthschaft jener Zeiten nach eingehenderen Forschungen keineswegs unansehnlich war.

Aristoteles und Thomas denken auch in der politischen Oekonomie an das $\equiv \tilde{j} \zeta_{5} \tilde{r}_{\nu}$, an das moralisch vollkommene, glück-

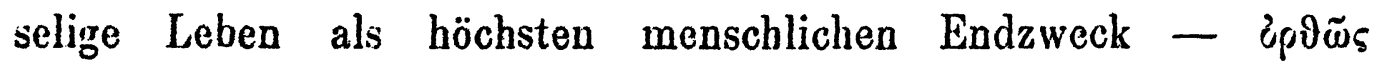
5Y,Tojis: 